\title{
Demonstration of the Coating Analysis Capabilities in Bison
}

\section{Nuclear Technology \\ Research and Development}

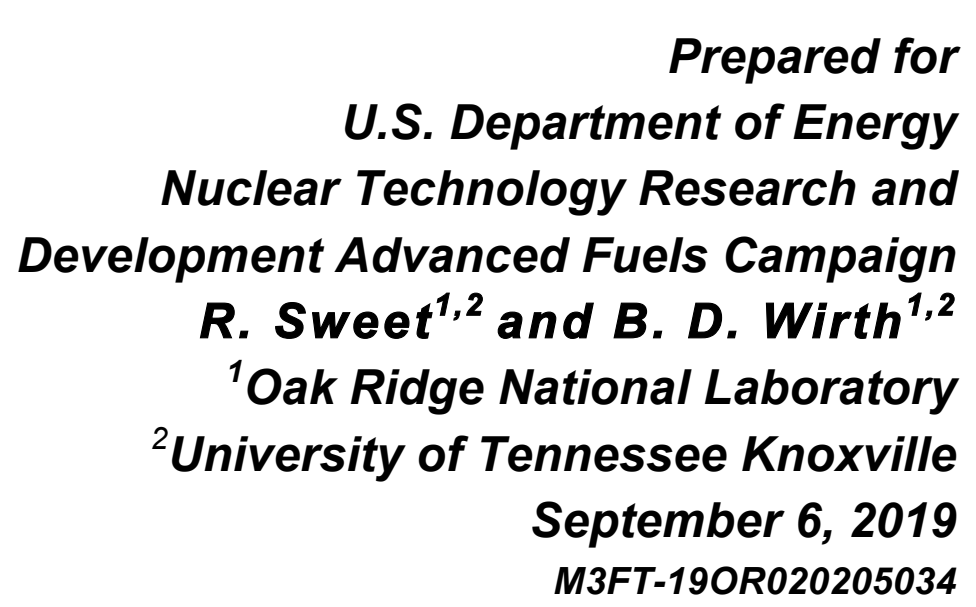

Approved for Public Release.

Distribution is Unlimited. 



\section{DISCLAIMER}

This information was prepared as an account of work sponsored by an agency of the U.S. Government. Neither the U.S. Government nor any agency thereof, nor any of their employees, makes any warranty, expressed or implied, or assumes any legal liability or responsibility for the accuracy, completeness, or usefulness, of any information, apparatus, product, or process disclosed, or represents that its use would not infringe privately owned rights. References herein to any specific commercial product, process, or service by trade name, trade mark, manufacturer, or otherwise, does not necessarily constitute or imply its endorsement, recommendation, or favoring by the U.S. Government or any agency thereof. The views and opinions of authors expressed herein do not necessarily state or reflect those of the U.S. Government or any agency thereof. 



\section{SUMMARY}

In order to improve the accident tolerance of light water reactor (LWR) fuel, coated cladding materials have been proposed which exhibit much slower oxidation kinetics in high-temperature steam than Zr-alloys. This behavior should decrease the energy release due to oxidation and allow the cladding to remain integral longer in the presence of high-temperature steam, making accident mitigation more likely. In order to determine how these coating materials will adjust the behavior of the Zr-alloy cladding during normal reactor operation, simulations have been performed using the Bison fuel performance code.

This analysis focused on modeling and comparing the integral thermo-mechanical performance of coated and uncoated zircaloy cladding with uranium dioxide fuel under normal operating conditions. This analysis demonstrates the ability to model a discrete meshed coating bonded to the cladding exterior and provides a comparison with an uncoated fuel rod. A generic range of coating material properties are implemented given the differences and unknowns regarding the proprietary coating properties used by the vendors. A main-effects analysis was performed to identify trends and sensitivities in how coating material properties affect key fuel performance metrics. Lastly, because residual stresses are expected to form in the coating, arising from the high temperature coating application process and application techniques, an additional analysis was performed to identify the impact of these stresses on the cladding behavior. Future analysis efforts will target more comprehensive documentation of this main effects analysis by sampling the results at the beginning and middle-of-life in order to capture important behavior before and during the onset of gap closure. 


\section{TABLE OF CONTENTS}

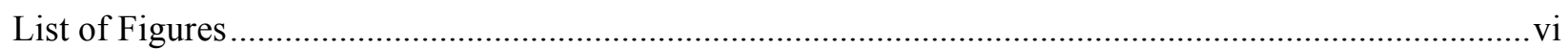

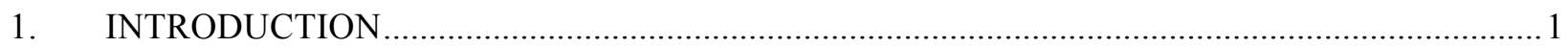

2. THERMO-MECHANICAL MODELING APPROACH ...............................................................2

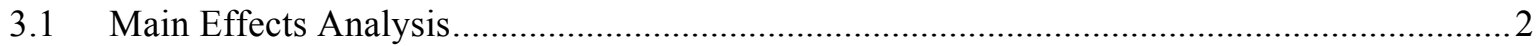

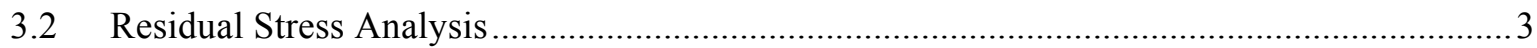

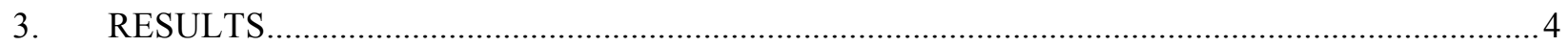

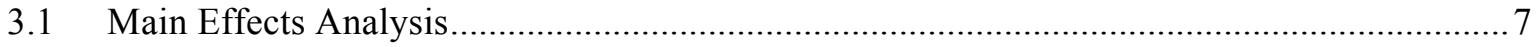

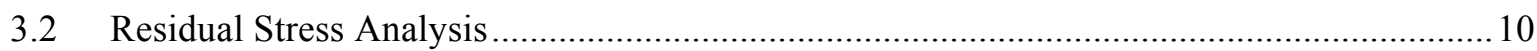

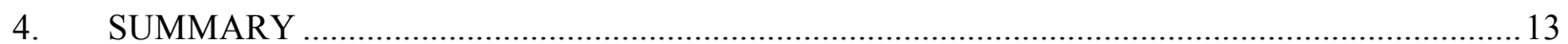

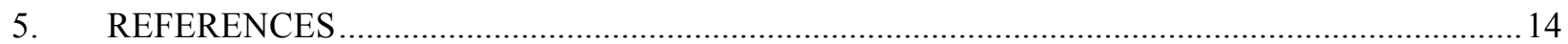




\section{LIST OF TABLES}

Table 1 - Parameters used in main effects simulations................................................................2

Table 2 - Nominal coating parameters used in comparison with uncoated cladding........................4 


\section{List of Figures}

Figure 1. The peak fuel centerline temperature (a) as a function of burnup initially, which has an $\sim 30 \mathrm{~K}$ increase due to the presence of the coating. The fuel-cladding gap (b) is initially larger in the coated cladding, and remains open to a larger burnup compared to a standard fuel rod.

Figure 2. Cladding axial displacement as a function of rod average burnup, comparing the nominal (uncoated) fuel rod to a rod with coated cladding (red, using nominal coating properties).

Figure 3. a) Maximum cladding hoop stress in the metallic zirconium cladding (a) for both the nominal fuel road (uncoated, blue line) and the coated cladding fuel rod (red line) with nominal properties. b) Maximum hoop stress in the nominal ceramic coating.

Figure 4. Main effects plots indicating the relative impact of each material property on the maximum fuel centerline temperature, in which the variable ceramic coating properties included coating thickness, coating thermal conductivity, coating elastic modulus, creep rate factor, and coefficient of thermal expansion (CTE).

Figure 5. Main effects plots indicating the relative impact of each material property on the maximum cladding hoop stress, in which the variable ceramic coating properties included coating thickness, coating thermal conductivity, coating elastic modulus, creep rate factor, and coefficient of thermal expansion (CTE).

Figure 6. Main effects plots indicating the relative impact of each material property on the maximum coating axial stress (red) and hoop stress (blue), in which the variable ceramic coating properties included coating thickness, coating thermal conductivity, coating elastic modulus, creep rate factor, and coefficient of thermal expansion (CTE).

Figure 7. The peak fuel centerline temperature (a) and (b) fuel cladding gap thickness as a function of burnup and the residual stress state in the ceramic coating.

Figure 8. The maximum cladding hoop stress (a) show a reduction in the compressing hoop stress for the more compressing coating residual stresses at low burnups. After gap closure occurs the cladding stress becomes tensile and shows similar behavior among all coating simulations. The maximum coating hoop stress (b) varies strongly based on initial residual stress and initially begins to converge due to cladding creep behavior until gap closure occurs and the hoop stresses become tensile. 


\section{INTRODUCTION}

During a severe accident scenario, such as a loss-of-coolant-accident, a light water reactor (LWR) may lose its capacity to cool its fuel. The fuel rod temperatures begin to increase, quickly reaching temperatures where the coolant begins to evaporate. This lowers the coolant level in the core and eventually uncovers the fuel. Without sufficient heat transfer from the fuel rods to the coolant, the temperature of the fuel and cladding will increase dramatically. In the case of traditional zirconium-based alloys, as the temperature of the cladding reaches $\sim 1204^{\circ} \mathrm{C}$ the zirconium rapidly begins to oxidize with $\mathrm{H}_{2} \mathrm{O}$ in the coolant and steam. This oxidation reaction causes both thinning of the $\mathrm{Zr}$-alloy cladding, as the metal reacts, and releases large amounts of $\mathrm{H}_{2}$ gas into the reactor pressure vessel.

In order to increase the safety margin of LWR fuel in severe accident scenarios, developing fuel system concepts with improved high-temperature oxidation resistance has become a priority for the domestic nuclear research community. These concepts range from new fuel and cladding materials to relatively modest changes, such as coatings on the cladding outer surface. As the development of these concepts continues, it has become clear that coating materials provide a near-term deployable strategy which may suffice until long-term solutions are ready.

For a coating to be successful, it must not negatively impact the normal operation of the zircaloy cladding (i.e. by substantially changing the thermo-mechanical or neutronic behavior of the cladding), and it must provide additional oxidation resistance. The ideal coating would remain completely adherent to the cladding, even in high-temperature scenarios where the cladding bursts due to creep rupture. This would effectively prevent the autocatalytic zircaloy oxidation reaction en masse, although surface imperfections, in-reactor debris, or grid-to-rod-fretting may cause the coating to wear, crack, and spall, exposing the cladding substrate.

In anticipation for upcoming work on coating materials, simulations have been performed demonstrating the ability of the Bison fuel performance code to analyze discrete meshed surface coatings. Because a variety of coatings have been proposed with a large range of properties, a main effects analysis has been performed. This analysis highlights the most sensitive coating material properties on selected fuel performance metrics. 


\section{THERMO-MECHANICAL MODELING APPROACH}

In order to assess the thermal and mechanical impact of a discrete meshed coating on the cladding substrate during normal operation and to provide a description of the performance impact arising from specific material properties of the coating layer, simulations have performed using the Bison fuel performance code. Bison is a finite-element based fuel performance code with a host of built-in material and behavioral models specific to LWR (and advanced reactor) fuel performance, and includes capabilities to simulate 1-, 2-, and 3-dimensional geometries [1, 2] For this analysis, the 2-D axisymmetric simulation capabilities are used. Default material models are used for the $\mathrm{UO}_{2}$ fuel and Zircaloy-4 cladding, as well as fuel rod behavioral models such as fission gas release. In order to simulate the coating, a discrete layer is meshed to the outside of the cladding and generic material properties are applied. To model creep in the coating, the Zircaloy4 thermal and irradiation creep model is used with a scale factor. Although this is not expected to provide an accurate portrayal of the creep behavior for these materials, little creep data exists for many proposed coating materials, and the results reported here are meant to demonstrate the modeling capability required to more thoroughly analyze specific coated cladding concepts.

For these simulations, the fuel rod operating conditions are modeled as a constant $18 \mathrm{~kW} / \mathrm{m}$ to a fuel rod average burnup of $60 \mathrm{MWd} / \mathrm{kgU}$. Reactor conditions are representative of a boiling water reactor and consist of a coolant temperature and pressure of $560 \mathrm{~K}$ and $7.136 \mathrm{MPa}$, respectively.

To identify the impact of the coating on the fuel rod performance, the fuel centerline, and cladding/coating deformation and stresses are used as metrics. These are chosen to demonstrate whether heat transfer from the fuel rod to the coolant is affected or the cladding creep-down, gapclosure and PCMI behavior are altered. This analysis consists of three separate evaluations: a detailed demonstration of a coating with nominal material properties, a main effects analysis of various coating material properties, and finally a parametric analysis of residual stress in the coating.

\subsection{Main Effects Analysis}

A main effects analysis has been performed by varying the coating thickness and material property models. Table 1 shows the parameters considered for these simulations. Values for these parameters come from a best estimate of the variation in the properties of proposed coatings. Aside from the coating thickness, the thermal conductivity, elastic modulus, thermal and irradiation creep rate and thermal expansion have all been varied. Each permutation of these values is simulated and grouped based on the parameter, the resulting metrics are then averaged. This shows the relative impact of the variation in the material models on the specific performance metrics.

Table 1 - Parameters used in main effects simulations.

\begin{tabular}{ccccc}
\hline Thickness $(\mu \mathrm{m})$ & $\begin{array}{c}\text { Thermal } \\
\text { Conductivity } \\
(\mathrm{W} / \mathrm{m}-\mathrm{k})\end{array}$ & $\begin{array}{c}\text { Elastic } \\
\text { Modulus } \\
(\mathrm{GPa})\end{array}$ & $\begin{array}{c}\text { Creep } \\
\text { Rate Scale } \\
\text { Factor }\end{array}$ & $\begin{array}{c}\mathrm{CTE} \\
\left(\mathrm{x} 10^{-6} \mathrm{~K}^{-1}\right)\end{array}$ \\
\hline 5 & 1 & 50 & 0 & 2 \\
27.5 & 10 & 200 & 0.01 & 7 \\
50 & 100 & 350 & 1 & 12
\end{tabular}


10

In order to perform this analysis, the Dakota code has been used to pre- and post-process the input and output files, and to submit the simulations to the computing cluster. In total, there are $405(3 \times 3 \times 3 \times 5 \times 3)$ simulations submitted for this evaluation. As a result, this analysis considers a very coarse variation in the material properties and, if deemed necessary, additional analyses will be performed in the future to fill the gaps. These simulations also consider a relatively coarse geometric mesh to limit the computational resources a finer mesh for this analysis would require.

\subsection{Residual Stress Analysis}

A series of simulations was performed using an applied isotropic stress and nominal coating material properties to assess the effect of residual stresses within the cladding coating on fuel rod integral performance. Values for the residual stress in this analysis $( \pm 1 \mathrm{GPa})$ were chosen to examine behavior extremes. Residual stresses arise from thermal expansion mismatch between the coating and substrate material, as well as the formation of temperature gradients and microstructural changes during the coating application process. This demonstration uses an arbitrary stress, unrelated to the thermal expansion mismatch between the coating and cladding, although future analyses will focus on identifying how the coating application process can impact the stress state and, consequently, the mechanical performance of the cladding. 


\section{RESULTS}

To demonstrate the impact of a generic coating on cladding thermo-mechanical performance, a simulation with a discrete meshed coating with nominal material properties, as identified in Table 2 is compared to a simulation with an uncoated fuel rod.

Table 2 - Nominal coating parameters used in comparison with uncoated cladding.

\begin{tabular}{ccccc} 
Thickness $(\mu \mathrm{m})$ & $\begin{array}{c}\text { Thermal } \\
\text { Conductivity } \\
(\mathrm{W} / \mathrm{m}-\mathrm{k})\end{array}$ & $\begin{array}{c}\text { Elastic } \\
\text { Modulus } \\
(\mathrm{GPa})\end{array}$ & $\begin{array}{c}\text { Creep } \\
\text { Rate Scale } \\
\text { Factor }\end{array}$ & $\begin{array}{c}\mathrm{CTE} \\
\left(\times 10^{-6} \mathrm{~K}^{-1}\right)\end{array}$ \\
\hline 27.5 & 10 & 200 & 0.1 & 7 \\
\hline
\end{tabular}

The peak fuel centerline temperatures (shown in Fig.1a) indicate an increase for the coated cladding fuel rod after the initial rise to operating power. This discrepancy reaches a maximum at nearly $25 \mathrm{MWd} / \mathrm{kgU}$, just before gap closure begins. After the onset of gap closure, the increase in fuel temperature arises from irradiation-induced thermal conductivity degradation of the fuel. The difference in the fuel centerline temperatures early in the simulation results from decreased cladding creepdown from the coating. Because the coating in this analysis has a lower creep rate than the zircaloy cladding, it acts to constrain the cladding, thereby reducing the amount of cladding creepdown. Fig. 1b shows the minimum gap distance across the fuel rod. Initially, the gap is reduced as the fuel expands more than the cladding from higher temperatures after the initial rise to operating power. Nearly immediately, the gap distance increases a small amount as the fuel begins to undergo irradiation-induced densification, which is completed by about $5 \mathrm{MWd} / \mathrm{kgU}$. Fission product swelling and cladding creepdown dominate gap closure during the initial stages of operation at steady-state power until the onset of pellet-cladding mechanical interaction. The gap of the coated cladding fuel rod remains larger, and open longer than the nominal, uncoated fuel rod since the coating, with these selected material properties, constrains cladding creepdown. For this analysis, a similar functional form for creep deformation of the coating has been implement as that of the cladding, but with a scale factor of 0.1 . As mentioned in the previous section, this model is not expected to accurately predict coating creep behavior, but there is little data available for either the thermal or irradiation creep of proposed coating materials. 

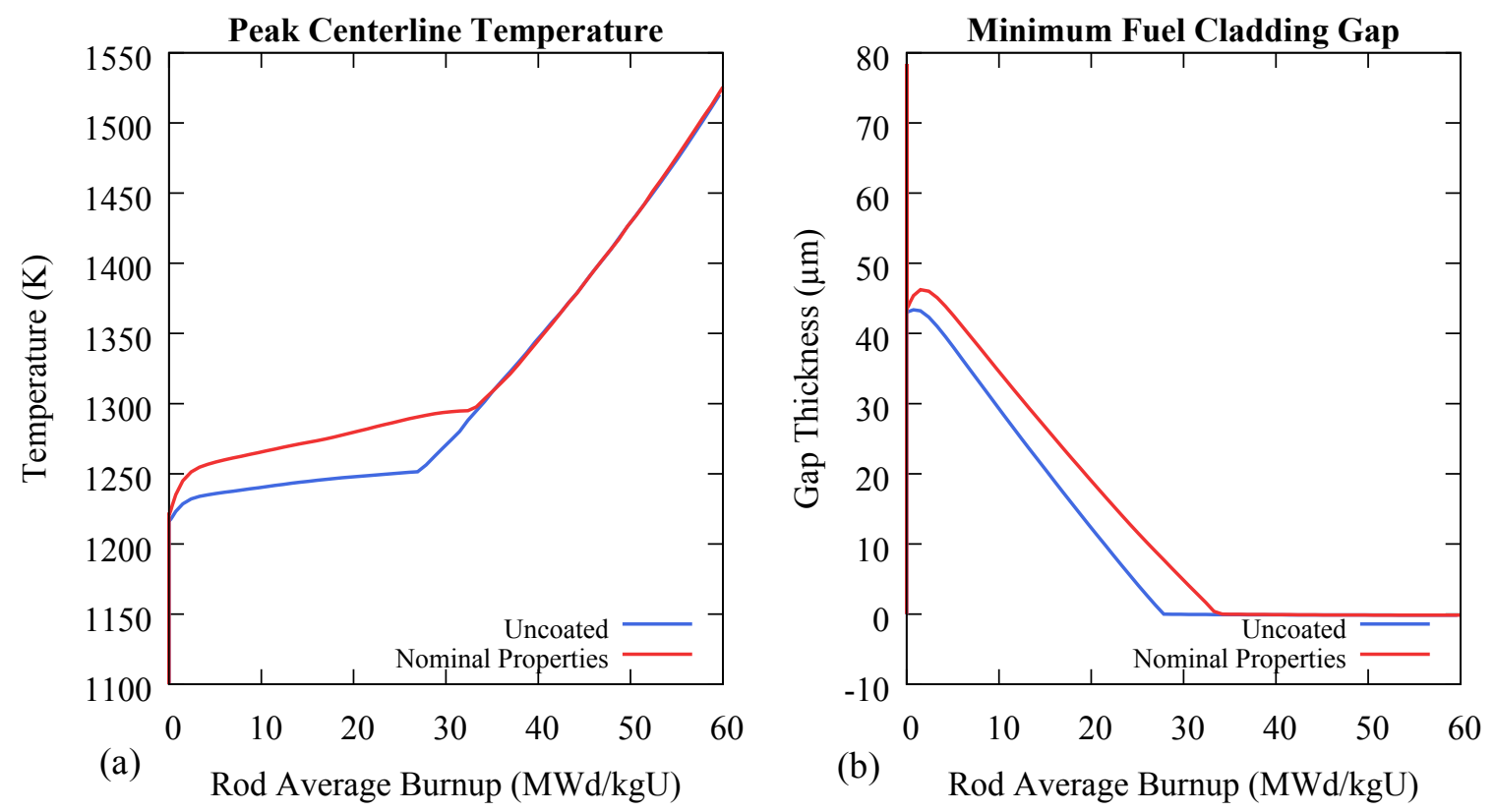

Figure 1. The peak fuel centerline temperature (a) as a function of burnup initially, which has an $\sim 30 \mathrm{~K}$ increase due to the presence of the coating. The fuel-cladding gap (b) is initially larger in the coated cladding, and remains open to a larger burnup compared to a standard fuel rod.

The cladding axial elongation (Fig. 2) behavior over the simulated steady power level of $18 \mathrm{KW} / \mathrm{m}$ and burnup also changes with the addition of the coating. Immediately, as the cladding temperature reaches the reactor coolant temperature, the mismatch in the thermal expansion between the coating and cladding acts to slightly increase the cladding length. This occurs because the coating thermal expansion coefficient is slightly larger than the Zircaloy- 4 , and initially induces a tensile axial stress in the cladding, with a corresponding compressive axial stress in the coating. The cladding continues to elongate with time in the nominal, uncoated fuel rod, while the coated cladding shows a significant reduction in the axial elongation toward the end of the simulation. Because there is no irradiation-induced dimensional change in the coating, it does not elongate over time. Instead, it provides additional rigidity to the cladding and acts to prevent additional deformation, which begins to occur by a burnup of about $15-20 \mathrm{MWD} / \mathrm{kgU}$. By the end of the simulation, the cladding in the coated rod has transitioned to an axially compressive stress state, while the axial stress in the coating experiences tension. 


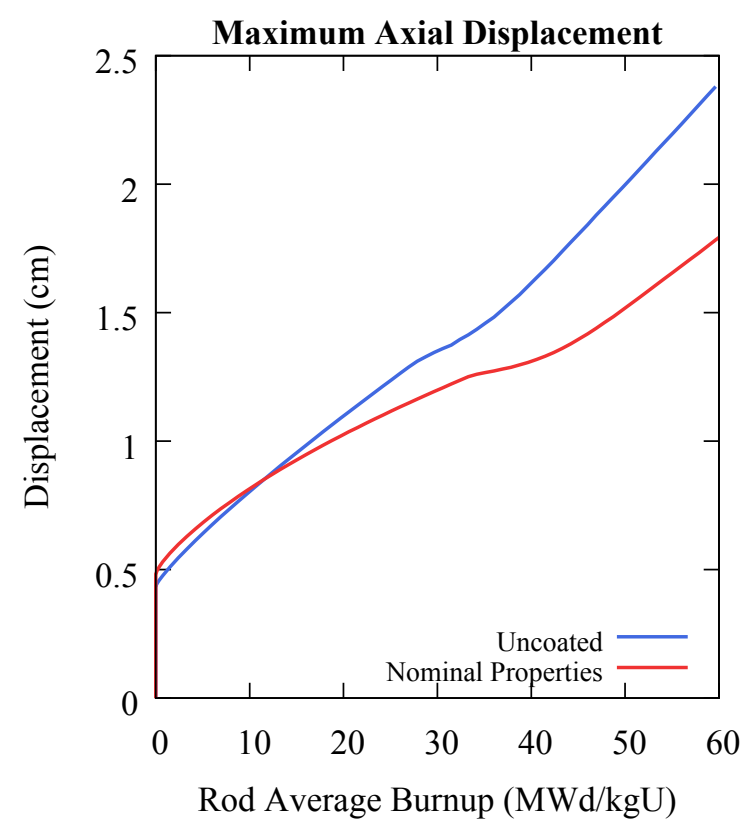

Figure 2. Cladding axial displacement as a function of rod average burnup, comparing the nominal (uncoated) fuel rod to a rod with coated cladding (red, using nominal coating properties).

The maximum hoop stress in the cladding is plotted in Figure 3, in which the maximum hoop stress in the zirconium metal is plotted in Fig. 3a and Fig. 3b plots this quantity in the ceramic coating. As indicated in Fig. $3 \mathrm{a}$, the effect of the mechanical constraint from the coating layer is to reduce the magnitude of the hoop stress in the zirconium metal. The hoop stress in the metallic cladding is initially compressive, driven by the pressure differential from the coolant and rod internal pressure, and the stress in the coated cladding is initially less compressive. As fission gas is released into the plenum, and the fuel cladding gap closes, the hoop stress in the metal cladding becomes tensile. The coated cladding experiences later gap closure, and the resulting tensile stress has a lower magnitude in the coated clad at later times, resulting from the constraint imposed by the ceramic coating. The maximum hoop stress in the coating (Fig. 3b) has a similar burnup dependence to the cladding, however the magnitude is much larger as a result of the thinner thickness of the coating. Near the end of the simulation, the coating shows very large tensile stresses due to the lack of creep deformation, since the nominal coating material properties in this model have essentially no thermal creep and a 0.1 factor for irradiation creep (relative to the Zircaloy-4 cladding). 

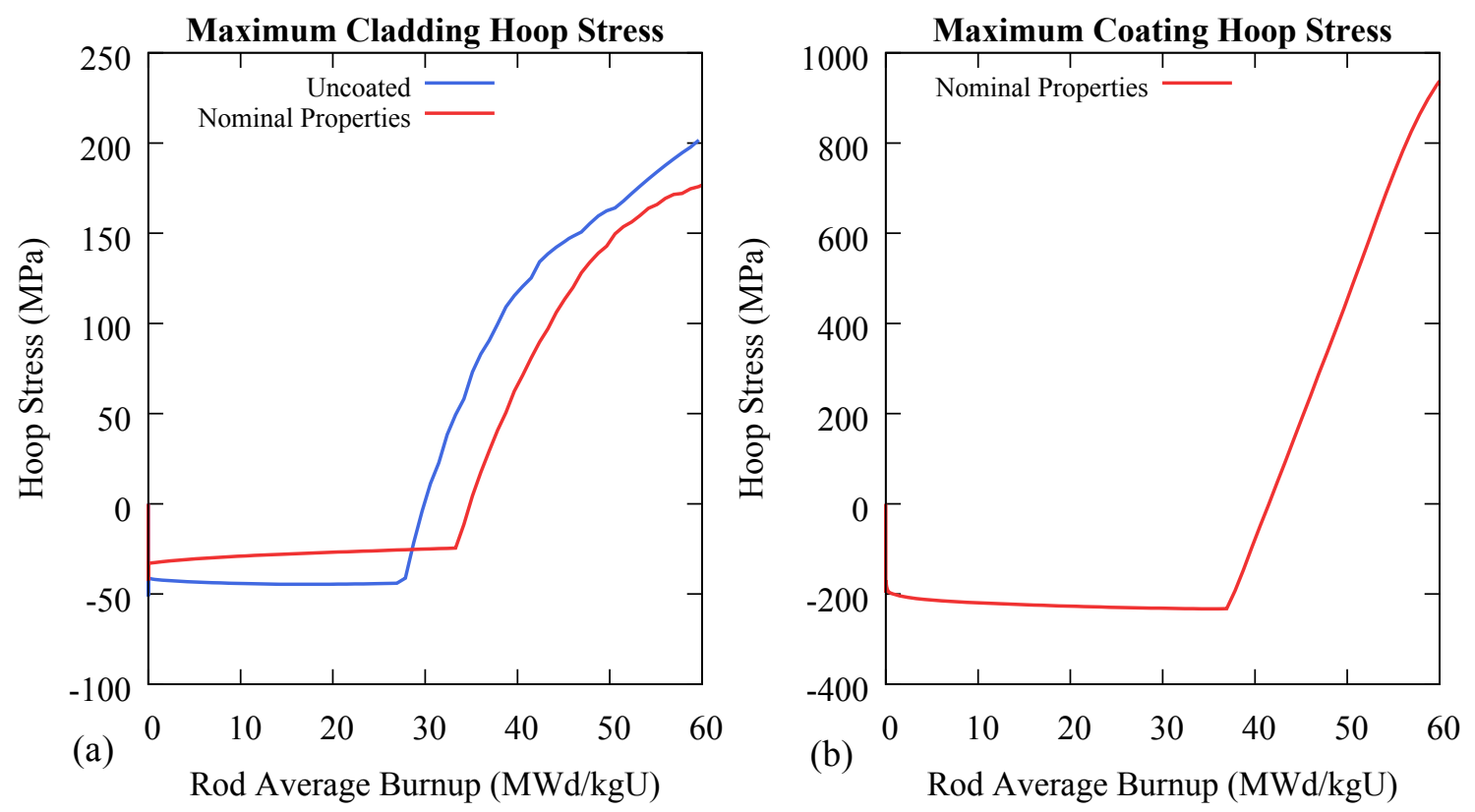

Figure 3. a) Maximum cladding hoop stress in the metallic zirconium cladding (a) for both the nominal fuel road (uncoated, blue line) and the coated cladding fuel rod (red line) with nominal properties. b) Maximum hoop stress in the nominal ceramic coating.

This analysis provides a comparison of a coated and uncoated cladding, demonstrating that a nominal coating provides additional structure to the fuel rod cladding, while limiting the cladding deformation. This describes a typical examination of the fuel and cladding performance using select performance metrics. It also demonstrates ability of Bison to model the coated cladding and provides an introduction for the data available for conducting the main effects on coating parameters, described in the next section.

\subsection{Main Effects Analysis}

In total, 405 simulations were performed using the same conditions from the previous section and data from each simulation was grouped by how the coating material property models/properties were varied. Performance metrics were then taken at the end of life (60 $\mathrm{MWd} / \mathrm{kgU}$ ) and averaged to provide a general trend for the impact of each parameter. In this section the fuel centerline temperature, cladding hoop stress, and coating stresses are examined. More parameters are available for this analysis, and will be reported on in the future. However, the parameters used were chosen as an example for their direct indication of the fuel rod performance.

Fig. 4 plots the variation in the peak fuel centerline temperature based of varying the coating properties. By increasing the coating thickness, regardless of the coating thermal conductivity, heat transfer between the fuel and coolant is impeded and the fuel centerline temperature will increase. This is illustrated by the relatively constant increase in the fuel temperature with increasing coating thickness. Likewise, for any coating thickness, the thermal conductivity will also have a direct impact on the fuel temperatures. The large jump in the temperature as the thermal conductivity is decreased indicates fuel centerline temperature is most 
sensitive to low thermal conductivity coatings. As shown in Figure 4, the coating elastic modulus, creep rate factor, and coefficient of thermal expansion (CTE) all have a relatively minor impact on the fuel temperatures (changes on the order of $5 \mathrm{~K}$ ), indicating only a limited impact on the fuel thermal performance. The results from these simulations, which are used to produce the main effects analysis plots, are sampled at the end-of-life $(60 \mathrm{MWd} / \mathrm{kgU})$ for each rod. Because this only provides a single state point for this rod over time, it does not show effectively demonstrate effects which are significant at the beginning or middle-of-life, such as the effects of coating properties on the creepdown and gap closure behavior of the Zircaloy cladding. Additional work will show the progression of these parameters, which are expected to change with the mechanical evolution of the fuel rod.
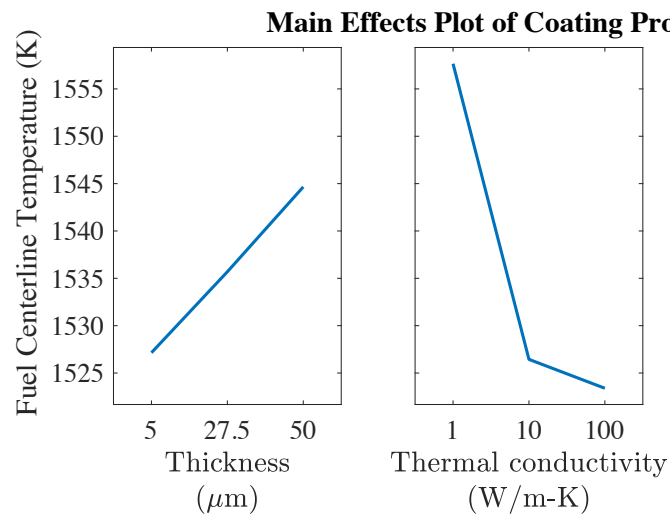

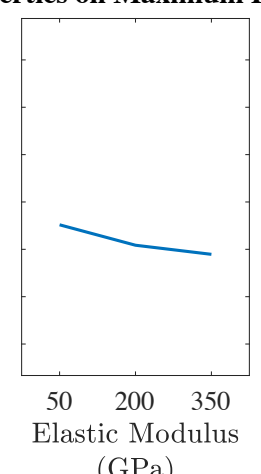

$(\mathrm{GPa})$

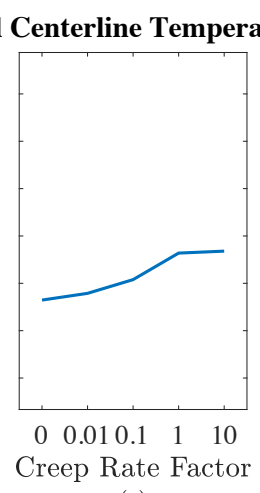

$(-)$

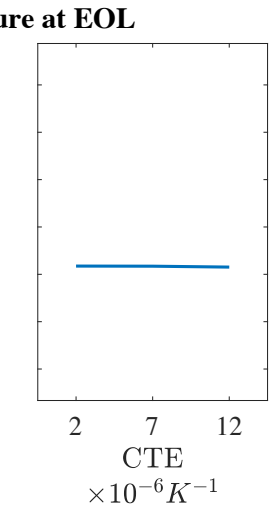

Figure 4. Main effects plots indicating the relative impact of each material property on the maximum fuel centerline temperature, in which the variable ceramic coating properties included coating thickness, coating thermal conductivity, coating elastic modulus, creep rate factor, and coefficient of thermal expansion (CTE).

Figure 5 plots a similar main effects plot, which is focused on the impact of varying the coating properties on the maximum cladding hoop stress. Again, coating thickness produces the largest impact on the cladding hoop stress (as with fuel centerline temperature). In these simulations, the cladding is in a tensile state (showing similar behavior to the previous section, particularly Fig 3a) because of the fuel expansion after the initiation of PCMI. As such, the increased cladding thickness from the coated cladding provides additional structure for the cladding, thereby decreasing the cladding hoop stress.

The thermal conductivity of the coating only shows an effect between 1 and $10 \mathrm{~W} / \mathrm{m}-\mathrm{K}$. Because the coating is thin (a maximum thickness of $50 \mu \mathrm{m}$ is considered here), the temperature increase due to the coating with thermal conductivity values above $10 \mathrm{~W} / \mathrm{m}-\mathrm{K}$ is small enough to have nearly no impact on the cladding hoop stress. At lower coating thermal conductivities, the cladding temperature is higher, resulting in a lower elastic modulus, more thermal expansion, and a high creep rate. The combination of these material properties acts to decrease the tensile cladding hoop stress as the temperature increases.

Similar to the coating thickness, the cladding hoop stress is reduced with increasing coating elastic modulus due to the ability for the coated cladding to withstand additional force from fuel expansion. The cladding hoop stress also shows a large impact with variations in the creep rate of the ceramic coating. The hoop stress is most sensitive to a creep rate between .1 and 1 (same creep rate range as Zircaloy). By increasing the amount of creep in the coating, the coating deforms more easily and provides less structure to the cladding. Conversely, by decreasing the creep rate scale factor the coating becomes more rigid, deforming less, and 
providing additional structural constraint to the cladding under deformation. The coating thermal expansion shows a negligible effect on the final cladding hoop stress.

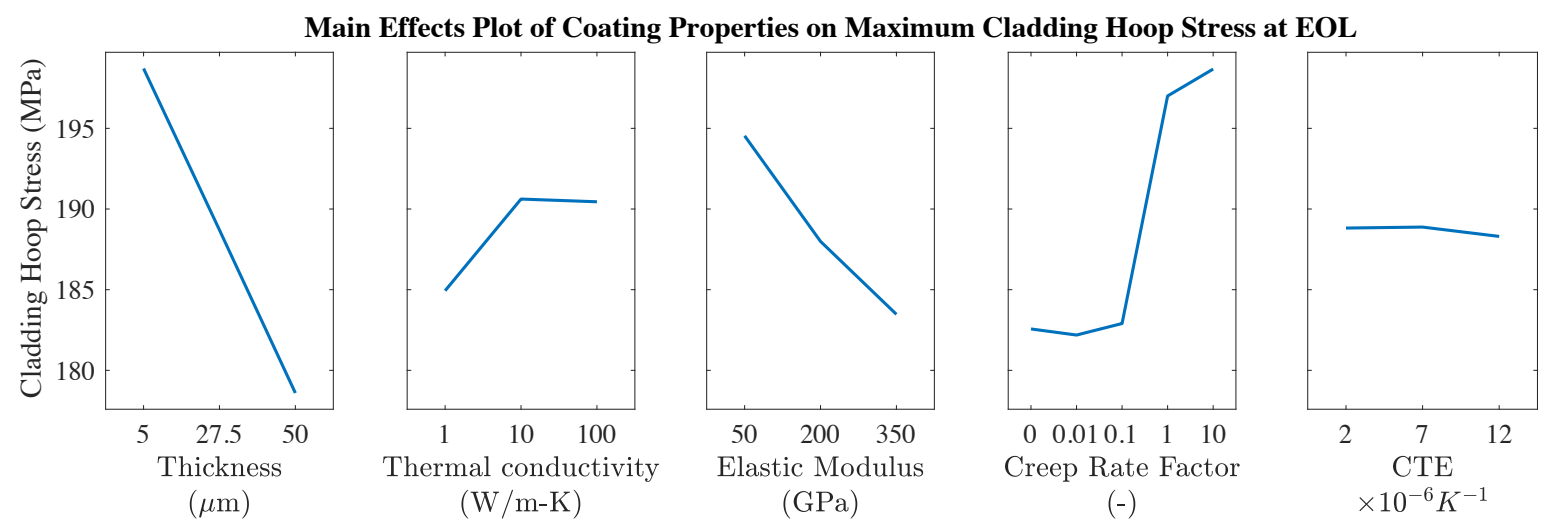

Figure 5. Main effects plots indicating the relative impact of each material property on the maximum cladding hoop stress, in which the variable ceramic coating properties included coating thickness, coating thermal conductivity, coating elastic modulus, creep rate factor, and coefficient of thermal expansion (CTE).

The main effects plots of the impact of varying coating properties on the coating axial and hoop stress at end-of-life (burnup $\sim 60 \mathrm{MWd} / \mathrm{kgU}$ ) are shown in Fig. 6 . This set of figures shows that the stress state in the coating is most sensitive to the elastic modulus and creep rate scale factor of the coating material, although these stresses (and the variation in the stresses) are well beyond the point many coating materials are expected to fail. As the elastic modulus is increased, the coating stress will increase more for a given elastic strain. This is because following gap closure the dominant loading force determining the strain and stress state in the cladding is fuel swelling induced displacement, rather than the pressure differential. The larger elastic moduli of the coating thus produce larger coating stresses. Likewise, the coating creep has an inverse effect. The more creep deformation, the more stress in the coating is relieved and the lower values that both the hoop and axial stresses are at the end-of-life. For these simulations, mechanical contact between the fuel and cladding is modeled as frictionless, so there is no locking or axial expansion as the fuel expands during PCMI. The creep rate in the coatings is modeled using the same phenomenological thermal and irradiation creep model as for Zircaloy-4, with a creep rate factor multiplier in these simulations. As previously mentioned, this assumption is not expected to provide an accurate representation of the coating creep, but provides an initial starting point in the absence of experimental data. As expected, increasing the coating thickness and thermal expansion coefficient both reduce the tensile axial and hoop stress development at the end-of-life. 

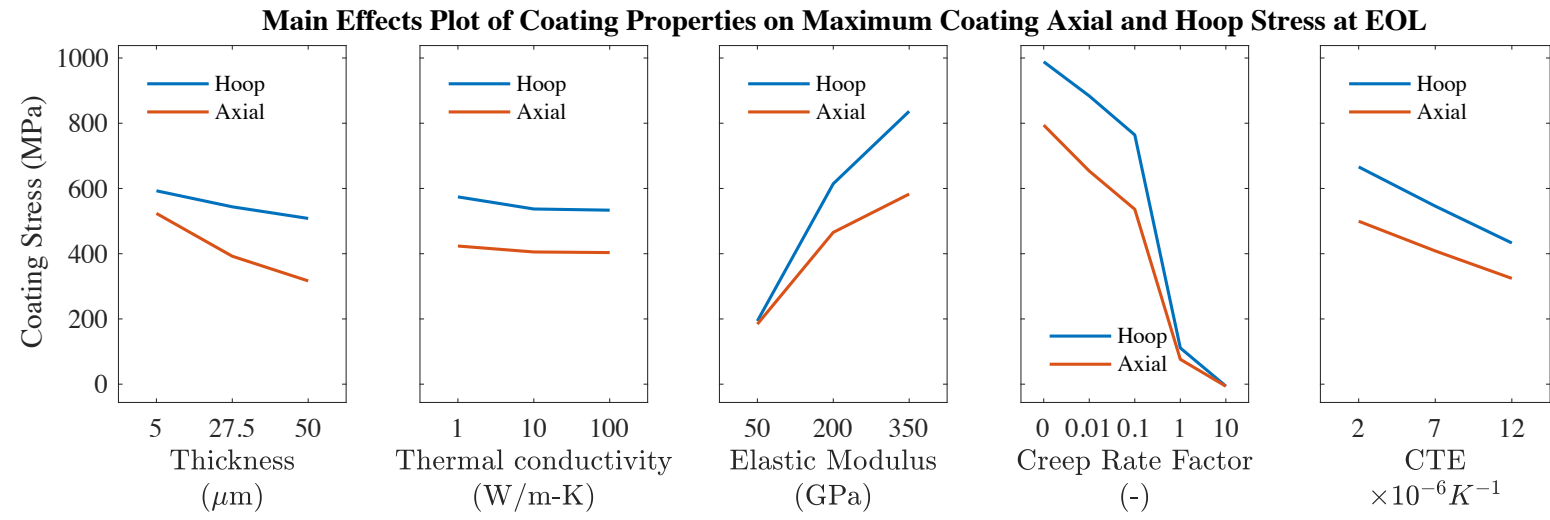

Figure 6. Main effects plots indicating the relative impact of each material property on the maximum coating axial stress (red) and hoop stress (blue), in which the variable ceramic coating properties included coating thickness, coating thermal conductivity, coating elastic modulus, creep rate factor, and coefficient of thermal expansion (CTE).

This analysis shows the impact of several coating material properties on the fuel rod thermal and mechanical behavior. The range of parameters used here has been defined by a best estimate assessment of the range of values expected in the proposed coating materials. For any permutation of these values, the maximum cladding hoop stress at the end-of-life only varies by approximately $20 \mathrm{MPa}$. While this does not provide any information about the change in creepdown behavior, it does highlight the coating impact on fuel performance after closure of the fuel cladding gap in the PCMI regime of fuel operation. It is worth noting that the thermal expansion model considered in this analysis uses a stress-free temperature of $293 \mathrm{~K}$, and therefore residual stresses are not included in this analysis. An effort to define the impact of the coating residual stress on the fuel rod performance is discussed in the following section.

\subsection{Residual Stress Analysis}

In order to determine how a residual stress in the coating layer will impact the integral fuel rod behavior, an additional set of simulations was performed. This set of simulations includes an isotropic stress applied to the coating at the beginning timestep. These simulations use the nominal coating material properties (Table 2), and the residual stress has been varied by \pm 1 and $\pm .5 \mathrm{GPa}$ between different simulations. This analysis uses an extremely fine geometry mesh, which results in slightly different displacements and stresses in the cladding from the previous analyses. This was performed to identify subtle differences in the performance metrics from the initial applied residual stress. Figure 7 shows the result of varying this residual stress on the maximum fuel centerline temperature and fuel cladding gap, while Figure 8 plots the impact on the maximum cladding and coating hoop stress, as a function of burnup.

Because the residual stresses used in this analysis are quite large and are assumed to be isotropic, the coating deforms the metallic portion of the cladding by a noticeable amount to achieve a force balance between the two layers. This causes the fuel cladding gap behavior to differ slightly, as shown in Fig. 7b, such that slightly larger gaps are maintained in the rods with larger compressive residual stresses, and the larger gaps in turn, result in slight modifications to the maximum fuel centerline temperature. Fig 7a. shows the peak fuel centerline temperatures as a function of burnup for this analysis. At the beginning of the simulations the temperatures vary 
based on the residual stress, in which the larger compressive residual stresses lead to slightly larger gaps and slightly higher fuel temperatures. Conversely, the tensile residual coating stresses are relieved as the material contracts, which closes the gap a small amount. This difference due to the residual stress is only noticeable until gap closure occurs, after which the fuel expansion becomes the dominant radial deformation mechanism in the cladding. After gap closure occurs, the fuel temperatures increase according to the burnup-induced thermal conductivity degradation of the fuel, and the dependence on coating residual stress is no longer observed. Fig. 7b shows the change in the gap behavior for these simulations. The subtle difference among these simulations corresponds to the applied stress until gap closure occurs.
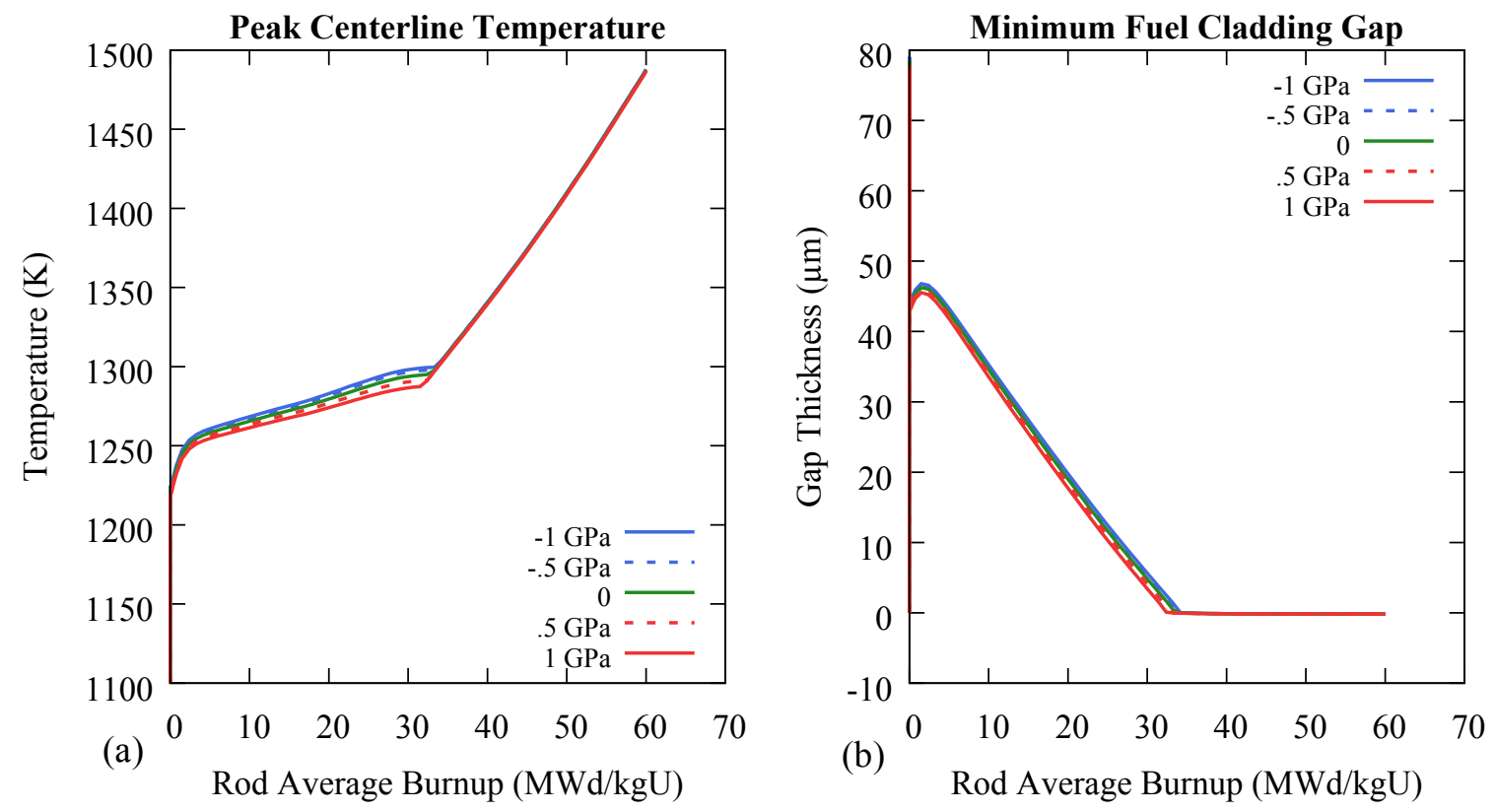

Figure 7. The peak fuel centerline temperature (a) and (b) fuel cladding gap thickness as a function of burnup and the residual stress state in the ceramic coating.

The maximum cladding hoop stresses (Fig. 8a) are initially compressive due to the pressure differential across the cladding. There is a variation in the simulations based on the residual stress in the coating. The coatings with the more compressive residual stresses have a slight expansion, and therefore exert an effective "pulling force" on the cladding that decreases the magnitude of the compressive stress due to the pressure differential until gap closure occurs. After gap closure occurs, the cladding hoop stresses converge as they increase and eventually begin to saturate. The coating hoop stresses (Fig. 8b) are quickly reduced in magnitude from the initial residual stress value, as the fuel rod reaches operating temperature and the coating begins to relieve stress through creep. Similar to the cladding, the coating transitions into a tensile stress state as gap closure occurs and the cladding is expanded by PCMI. 

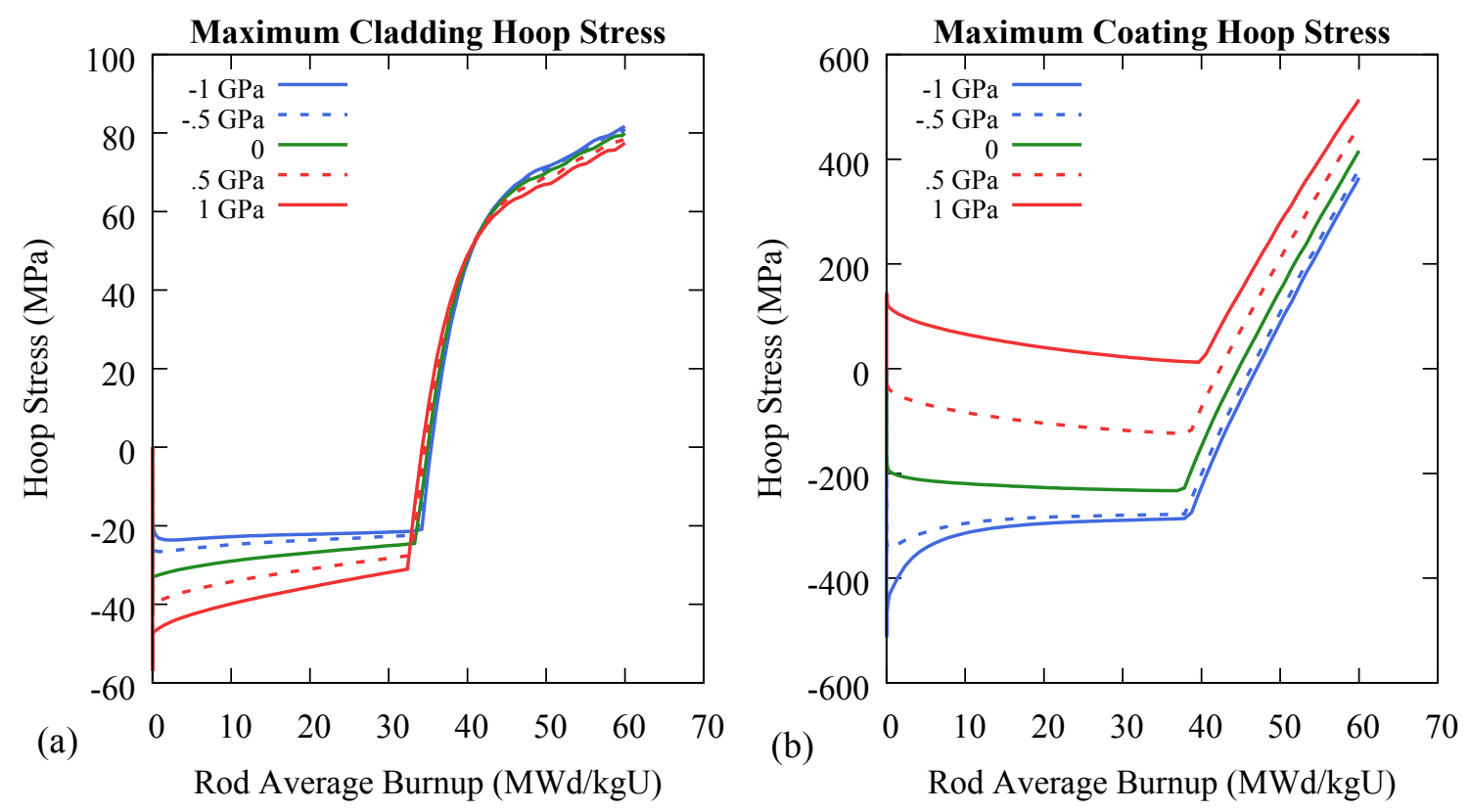

Figure 8. The maximum cladding hoop stress (a) show a reduction in the compressing hoop stress for the more compressing coating residual stresses at low burnups. After gap closure occurs the cladding stress becomes tensile and shows similar behavior among all coating simulations. The maximum coating hoop stress (b) varies strongly based on initial residual stress and initially begins to converge due to cladding creep behavior until gap closure occurs and the hoop stresses become tensile.

Within the cladding, the coating residual stress (for these specific coating properties) shows very little impact. The coating stress state through the simulation, however, does show an impact from the residual stress, although it is less sensitive to progressively larger compressive stresses. However, it is important to note that this initial analysis has assumed an initial isotropic residual stress state, and thus further analysis is required to assess the impact of a more realistic anisotropic residual stress. Residual stress can be used as an engineering parameter to be changed using different coating application techniques. As such, it may be useful to perform additional analyses to determine the optimum stress-state for cladding applications. 


\section{SUMMARY}

This milestone demonstrates the ability of Bison to analyze the performance of fuel rods containing a ceramic coating and sets the stage for a more in-depth analysis of coating materials in conjunction with laboratory experiments. This highlights that a framework is in place to begin implementing data from experiments and test conditions to isolate specific areas of coating performance. This analysis included a detailed demonstration of a generic coating material with nominal material properties, a main effects analysis of various coating material properties on select fuel performance metrics, and finally a parametric variation of residual stress in the coating. From this analysis, it is clear that the creep behavior of the coating, in addition to the elastic properties have the largest impact on the stress state in the cladding. This analysis focuses on the impact of the coating on the fuel and cladding behavior during normal operation and does not include any form of coating failure. Future analyses on coating performance using Bison will focus on the development and application of failure criterion for the coating, such as cracking and delamination from the cladding surface. 


\section{REFERENCES}

1. Williamson, R.L., et al., Multidimensional multiphysics simulation of nuclear fuel behavior. Journal of Nuclear Materials, 2012. 423(1-3): p. 149-163.

2. Hales, J., et al., BISON theory manual: The equations behind nuclear fuel analysis. 2014, Fuels Modeling \& Simulation Department, Idaho National Laboratory, Idaho Falls, Idaho. 